\title{
Antibiotics prescribed by health care workers for children under 5 years with respiratory symptoms in rural areas in Kyrgyz Republic.
}

A FRESH AIR study.

Elvira Isaeva, Azamat Akylbekov, Marianne Stubbe Østergaard, Jesper Kjærgaard, Susanne Reventlow, Talant Sooronbaev.

Irrational use of antibiotics is a serious problem in Kyrgyzstan and

internationally.

The use of antibiotics for the treatment of viral infections, such as influenza promotes the emergence of resistant strains of bacteria.

In 2014, the Kyrgyz Ministry of Health issued an order limiting the selling of antibiotics by pharmacists without prescription. However, this decision is not being adhered to.

The aim of this study was to describe how often antibiotic therapy is prescribed for viral upper respiratory tract infections in rural areas of Kyrgyzstan among children under 5 years.

\section{Methods}

The study was conducted in health clinics in rural areas of Kyrgyzstan. We screened 494 children between 2 to 59 months who consecutively came to medical centers. Of these, we included 232 children with cough and/or breathing difficulties.

We observed the consultations of these children by a medical worker - a family medicine doctor, a feldsher (medical assistant) or a nurse. We recorded the diagnosis given and what treatment was prescribed.

\section{Results}

We screened 494 children. We included $232(47 \%)$ children in the study.

Of these, most were diagnosed with a viral infection, and 114 (49\%) received antibiotics.

\begin{tabular}{|l|l|}
\hline \multicolumn{2}{|c|}{$\begin{array}{c}\text { Table 1: Age and gender of children } \\
\text { included }(\mathrm{N}=232)\end{array}$} \\
\hline Gender: & $\%$ \\
\hline Female & 52,0 \\
\hline Male & 48,0 \\
\hline Age: & \\
\hline Up to 6 months & 15,8 \\
\hline 6 to 12 months & 13,0 \\
\hline 12 to 59 months & 71,2 \\
\hline
\end{tabular}

Table 2: Presenting symptoms and diagnoses assigned to children included $(\mathrm{N}=232)$

Presenting symptoms: $\%$

\begin{tabular}{|l|l|}
\hline Cough & 100 \\
\hline Difficulty breathing & 5,0 \\
\hline Fever & 33,1 \\
\hline Diagnosis: & \multicolumn{2}{|l|}{} \\
\hline Viral infections & 72,7 \\
\hline Common cold & 5,6 \\
\hline Bronchitis & 18,1 \\
\hline Pneumonia & 1,2 \\
\hline Other & 2,4 \\
\hline
\end{tabular}

\section{Discussion}

Irrational use of antibiotics could be because lack of knowledge regarding resistance to antibiotics is widespread.

During the data collection we discovered that many parents themselves administered antibiotics to their children, without examination and consultation of a doctor. Unfortunately we did not document it because we did not anticipate it.

This could explain why some health care workers decided to continued antibiotics therapy for a viral infection.

\section{Conclusion}

Overall, the study found widespread irrational use of antibiotics.
This study indicates the need for: Training of primary health care workers in rural areas of Kyrgyzstan on the indication of the prescription of antibacterial medicine.

Development of clinical protocols on the use of antibacterial medicines for children with respiratory symptoms

To conduct educational work among the population and parents.

Teaching materials for parents, showing the outcome of self-treatment at home and the uncontrolled use of antibacterial drugs.

Ministry of Health should continue to work to stop the sale of antibiotics without prescription.

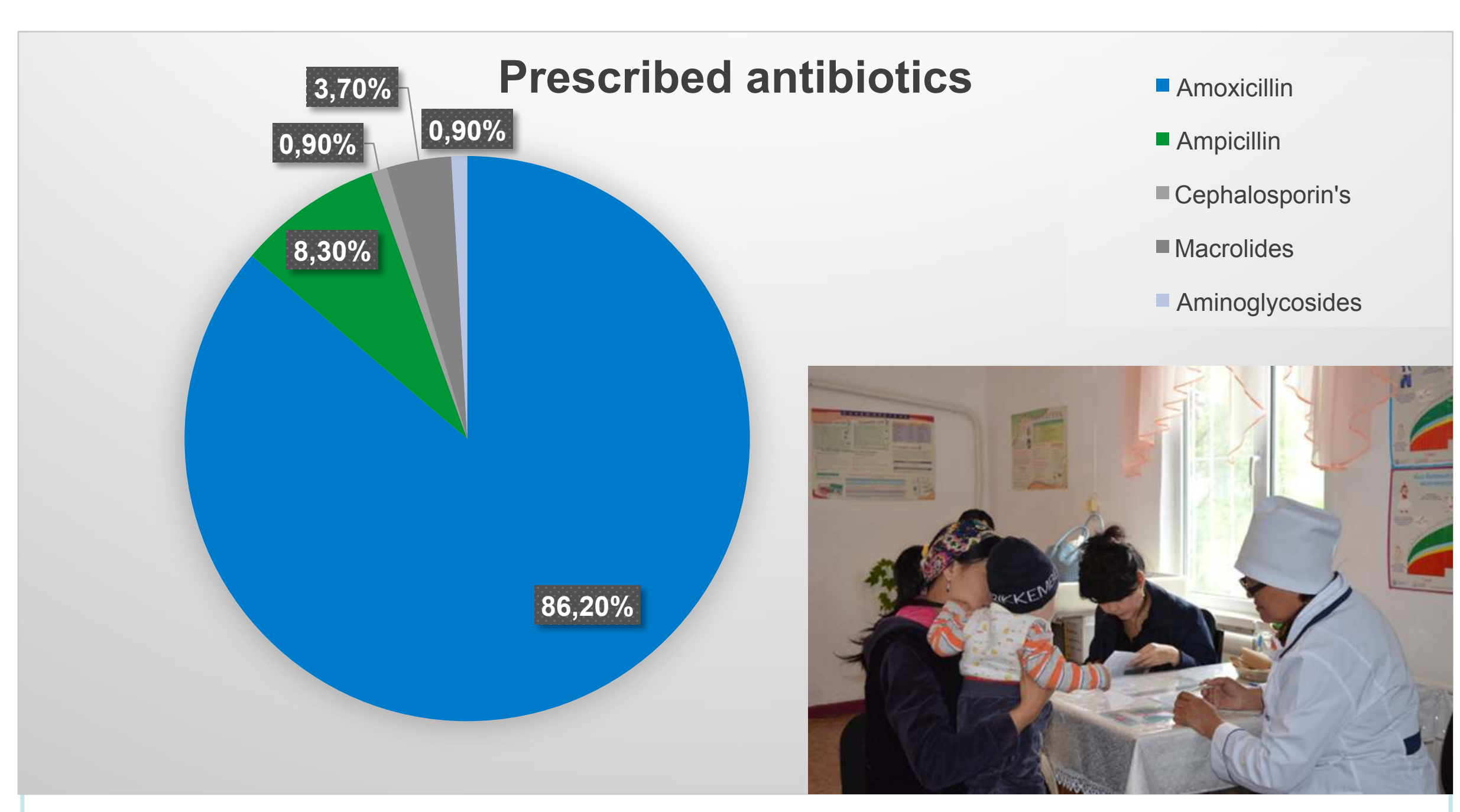

